\title{
The hexadehydro-Diels-Alder (HDDA) cycloisomerization reaction proceeds by a stepwise mechanism
}

\author{
Tao Wang, Dawen Niu, and Thomas R. Hoye ${ }^{\star}$ \\ Department of Chemistry, University of Minnesota, Minneapolis, Minnesota 55455
}

\begin{abstract}
We report here experiments showing that the hexadehydro-Diels-Alder (HDDA) cycloisomerization reaction proceeds in a stepwise manner-i.e., via a diradical intermediate. Judicious use of substituent effects was decisive. We prepared: (i) a series of triyne HDDA substrates that differed only in the group, $\mathrm{R}$, present on the remote terminus of the diynophilic alkyne and (ii) an analogous series of dienophilic alkynes $\left(n-\mathrm{C}_{8} \mathrm{H}_{16} \mathrm{COC} \equiv \mathrm{CR}\right)$ for use in classical Diels-Alder (DA) reactions (with 1,3-cyclopentadiene). The R groups were: $\mathrm{CF}_{3}, \mathrm{CHO}, \mathrm{COMe} / \mathrm{Et}$, $\mathrm{CO}_{2} \mathrm{Me}, \mathrm{CONMe}_{2} / \mathrm{Et}_{2}, \mathrm{H}$, and 1-propynyl. The relative rates of both the HDDA cyclization reactions and the simple DA cycloadditions were measured. The reactivity trends revealed a dramatic difference in the behaviors of the $\mathrm{CF}_{3}$ (slowest HDDA and nearly fastest DA) vs. 1propynyl (fastest HDDA and slowest DA) containing members of each series. These differences can be explained by invoking radical-stabilizing energies rather than electron-withdrawing effects as the dominating feature of the HDDA reaction.
\end{abstract}

The hexadehydro-Diels-Alder (HDDA) reaction is the most highly oxidized variant of the classic Diels-Alder [4+2] cycloaddition reaction. ${ }^{1}$ In the latter, a 1,3-diene is engaged by a dienophile; in the former, a 1,3-diyne by an alkynyl diynophile. ${ }^{2}$ The latter typically results in cyclohexene formation; the HDDA reaction leads to benzyne (or hexadehydrocyclohexene) formation (1 to 2, Figure 1a). A significant added dimension of the HDDA variant arises from the rich plethora of trapping reactions that make arynes a highly versatile and valuable reactive intermediate. By comparison, all other members of the family of all-carbon Diels-Alder reactions engender new six-membered carbocycles that are at a stable oxidation state-cyclohexene, cyclohexadiene, or benzene depending upon whether 0,1 , or 2 alkynes are present, collectively, in the $2 \pi$ - and conjugated $4 \pi$-reaction partners. ${ }^{3}$ We refer to the overall tandem process of HDDA cycloisomerization of a triyne followed by a benzyne trapping reaction as an HDDA cascade (1 to $\mathbf{2}$ to $\mathbf{3}$ ). ${ }^{4}$ The initial HDDA cycloisomerization reaction is the rate-limiting event. The HDDA cascade is powerful for many reasons (e.g., constitutes a synthetic strategy for de novo construction of benzenoid rings; allows facile access to benzynes of considerably more complicated

\footnotetext{
*Corresponding Author hoye@umn.edu. ASSOCIATED CONTENT

Supporting Information

The Supporting Information is available free of charge on the ACS Publications website.

New compound preparation, spectroscopic characterization data, and copies of ${ }^{1} \mathrm{H}$ and ${ }^{13} \mathrm{C}$ NMR spectra (PDF).

The authors declare to have no competing financial interests.
} 
structure compared to those from classical benzyne generation; can enable the discovery of new types of trapping reaction; and can serve as a platform for multicomponent processes ${ }^{5}$ ). As for any new reaction process and especially so for those with broad applicability, it is valuable to know the underlying mechanistic details that govern reactivity.

Computational [density functional theory (DFT)] studies have been used to explore aspects of the mechanism of the HDDA cycloisomerization reaction. ${ }^{6}$ These encompass both (hypothetical) intermolecular as well as prototypical intramolecular examples. The calculations indicate that the activation energies for stepwise and concerted processes are similar, although a preference for a stepwise mechanism through a diradical intermediate ${ }^{7}$ was often seen. We used ${ }^{6 e}$ the relative rates of cyclizations of a series of esters 4 to give, ultimately, the phthalide lactones 5 (Figure 1b) to guide our choice of an optimal method ${ }^{6 f}$ to account for measured experimental reactivities. The transition state (TS) geometry for the concerted process for the specific case of ester $4\left(R^{1}, R^{2}=H\right.$; magenta) was $6 \mathrm{kcal} \bullet \mathrm{mol}^{-1}$ higher in energy than the TS leading from 4 to the diradical $\mathbf{6}$. The closure of $\mathbf{6}$ to 5 was nearly barrierless. In other words, this computation suggests that $\mathbf{6}$ is extremely short-lived, which, incidentally, is consistent with the fact that we have seen no consequences of radical character in any of the many modes of HDDA trapping reactions we have studied.

In the study reported here, we decided to systematically evaluate diynophile substituent effects on the rate of the HDDA reaction to see whether experimentation could distinguish between a stepwise vs. concerted reaction pathway. Accordingly, we identified the series of triynes 7a-g (Figure 2a) as an appropriate group of compounds for measuring their relative rates of HDDA cyclization. The choice of this set of substituents was guided by the prevalent use of many as activators of classical Diels-Alder reactions. The inclusion of the alkynyl substituent in tetrayne $7 \mathbf{f}$ was based on the observation of Houk and coworkers that an alkynyl substituent on the terminus of the diynophile significantly lowered the activation barrier computed for the HDDA reaction for the intermolecular HDDA net cycloaddition reaction of 1,3-butadiyne with itself vs. with ethyne. ${ }^{6 b}$

Diynamide substrates like $\mathbf{7}$ are known to be well behaved, cyclizing at convenient rates and giving rise to indoline products in good yields. ${ }^{1,8}$ The products $9 \mathbf{9}-\mathbf{g}$ are formed via the HDDA cascade comprising initial, rate-limiting cycloisomerization of $\mathbf{7}$ to benzynes $\mathbf{8}$ followed by rapid trapping by the pendant silyl ether. In every instance, product 9 was, by far, the major product formed and, most often, the only product observed. The yields of $9 \mathbf{a}-\mathbf{g}$ following isolation ranged from $42-82 \% .^{9}$

The relative rates of the HDDA cyclization were determined by ${ }^{1} \mathrm{H}$ NMR spectroscopic analysis of reactions performed in toluene- $d_{8}$ at $110{ }^{\circ} \mathrm{C} .{ }^{10}$ Integration of the growth of resonances from products 9 vs. those of an inert internal standard ( $p$-nitrotoluene) as a function of time allowed identification of the reaction half-lives. These are listed in Table 1.

First, consider the reactivities within the set 7a-e. These correlate reasonably well with the expected substituent effects (see below) in classical Diels-Alder dienophile activation (i.e., approximately, $\mathrm{CHO}>\mathrm{COR}>\mathrm{CO}_{2} \mathrm{R}>\mathrm{CONR}_{2}>\mathrm{H}$ ). This trend is also suggested by comparison to the Hammett $\sigma_{p}$ values, ${ }^{11}$ which reflect the electron withdrawing character of 
the groups present in 7a-e. It is tempting to be satisfied that this trend mirrors that of dienophile reactivity in classical Diels-Alder reactions. ${ }^{12}$ However, a less often used parameter, the radical stabilizing energy (RSE), ${ }^{13}$ is also given in Table 1 . These also are, qualitatively, in line with the reactivity trend observed for 7a-e. We return below to consider the rates of the alkynyl- and trifluoromethyl-bearing triynes $\mathbf{7 f}$ and $\mathbf{7 g}$.

How well do the relative HDDA reactivities for the specific set of $\mathbf{7 a - g}$ compare with dienophile substituent effects in classical Diels-Alder cycloadditions? We were surprised to find a relative paucity of data addressing, in a quantitative way, dienophilic reactivity in a set of analogs in which only a single substituent has been varied. In fact, we can find only two reports of such studies ${ }^{14}$ and neither encompassed the array of substituents we desired for comparison with the full set of analogs 7a-g. Therefore, we prepared the series of electron deficient alkynes 13a-g (see SI). These again differ only in the substituents $\mathrm{R}$, the nature of which corresponds directly to those in triynes 7a-g. Competition studies were used to determine, in pairwise fashion, the relative reactivities of these dienophiles. We used the classic approach of exposing a substantial excess of each of the two competing reactants, in this case 10 equiv each of two different dienophiles $\mathbf{1 3}$, with the limiting reactant, here cyclopentadiene (14). Under the assumption that the reaction is essentially irreversible, the product ratio is a direct reflection of the relative rate constants for the two competing DA reactions, because the initial relative concentration of both dienophiles remains nearly constant throughout the course of the reaction.

The dienophiles are listed in Table 2 in order of decreasing reaction rate (red to blue). Note that the propynyl substituted compound $\mathbf{1 3 f}$ is the slowest of all ${ }^{6 \mathrm{~b}}$ and that the trifluoromethylated alkyne $\mathbf{1 3 g}$ is one of the fastest. The Hammett $\sigma_{\mathrm{p}}$ and RSE parameters are also listed. The results are much better aligned with the electron withdrawing nature of the substituent, as expressed by $\sigma_{\mathrm{p}}$, rather than with their radical stabilizing character, as reflected in the RSE values.

What have we learned from the HDDA reactivity of compounds $\mathbf{7 f}$ and $\mathbf{7 g}$ vis-à-vis the rates of Diels-Alder cycloaddition of the ynones $13 \mathbf{f}$ and $\mathbf{1 3 g}$ ? Indeed, it was the dichotomous nature of the electron withdrawing $\left(\sigma_{\mathrm{p}}\right)$ vs. the radical stabilizing effects (RSEs) of alkynyl vs. $\mathrm{CF}_{3}$ substituents (see Table 1) that led us to include tetraynes $\mathbf{7 f}$ and $\mathbf{7 g}$ among the HDDA substrates we studied. The results are quite definitive. The tetrayne $\mathbf{7 f}$, whose alkynyl substituent has the largest RSE but only negligible electron withdrawing power, reacts the fastest, and the trifluoromethylated alkyne $\mathbf{7 g}$, with its non-radical-stabilizing and strongly electron withdrawing $\mathrm{CF}_{3}$ substituent, the slowest (Table 1, red vs. blue, respectively) of all the HDDA substrates we studied. This is clearly supportive of a stepwise mechanism for the HDDA cycloisomerization reaction, in which the substrate $\mathbf{1 6}$ proceeds via an initial (and rate-determining) closure to the diradical intermediate $\mathbf{1 8}$ via "stepwise TS1" rather than proceeding directly to benzyne 17 via the "concerted TS" (Figure 3). This conclusion is in accordance with earlier computational analyses. ${ }^{6 \mathrm{~b}, \mathrm{c}, \mathrm{e}}$ Finally, recall that those studies also indicated that recombination within the diradical 18 to complete the formation of the carbocyclic benzyne occurs with an extremely low activation barrier. Circumstantial evidence supports this view; we have never observed a product from any HDDA cascade experiment 
that suggests that diradical $\mathbf{1 8}$ is of any practical consequence. All told, our experimental data validate the mechanistic pathway laid out in Figure 3 for the HDDA cycloisomerization.

\section{Supplementary Material}

Refer to Web version on PubMed Central for supplementary material.

\section{ACKNOWLEDGMENT}

This research was supported by the National Institutes of Health (GM65597). NMR spectral data were collected with instrumentation acquired through the NIH Shared Instrumentation Grant program (S10OD011952). T. W. received support from a Wayland E. Noland Fellowship; T. W. and D. N. each received support from a University of Minnesota Graduate School Doctoral Dissertation Fellowship.

\section{REFERENCES}

1. Baire B, Niu D, Willoughby PH, Woods BP, Hoye TR. Nat. Protoc. 2013; 8:501-508. [PubMed: 23411632]

2. a Bradley AZ, Johnson RP. J. Am. Chem. Soc. 1997; 119:9917-9918.b Miyawaki K, Suzuki R, Kawano T, Ueda I. Tetrahedron Lett. 1997; 38:3943-3946.c Tsui JA, Sterenberg BT.

Organometallics. 2009; 28:4906-4908.

3. Wessig P, Müller G. Chem. Rev. 2008; 108:2051-2063. [PubMed: 18479169]

4. Hoye TR, Baire B, Niu D, Willoughby PH, Woods BP. Nature. 2012; 490:208-212. [PubMed: 23060191]

5. Bhunia A, Yetra SR, Biju AT. Chem. Soc. Rev. 2012; 41:3140-3152. [PubMed: 22278415]

6. Ajaz A, Bradley AZ, Burrell RC, Li WHH, Daoust KJ, Bovee LB, DiRico KJ, Johnson RP. J. Org. Chem. 2011; 76:9320-9328. [PubMed: 21977993] Liang Y, Hong X, Yu P, Houk KN. Org. Lett. 2014; 16:5702-5705. [PubMed: 25329369] Kerisit N, Toupet L, Larini P, Perrin L, Guillemin J-C, Trolez Y. Chem.-Eur. J. 2015; 21:6042-6047. [PubMed: 25761250] Skraba-Joiner SL, Johnson RP, Agarwal J. J. Org. Chem. 2015; 80:11779-11787. [PubMed: 26418846] Marell DJ, Furan LR, Woods BP, Lei X, Ben delsmith AJ, Cramer CJ, Hoye TR, Kuwata KT. J. Org. Chem. 2015; 80:11744-11754. [PubMed: 26270857] [ [SMD( $o$-dichlorobenzene)/B3LYP-D3BJ/6-311+G(d,p)// M06-2X/6-311+G(d,p)]

7. For a review describing cycloaromatization reactions via diradicals, see: Mohamed RK, Peterson PW, Alabugin IV. Chem. Rev. 2013; 113:7089-7129. [PubMed: 23600723]

8. Yun SY, Wang K-P, Lee N-K, Mamidipalli P, Lee D. J. Am. Chem. Soc. 2013; 135:4668-4671. [PubMed: 23477300]

9. In the case of the slowest reacting members, format ion of 3-butynyl $p$-toluenesulfonamidecontaining byproducts were observed, presumably arising from a slow hydrolysis of the ynamide bond in $\mathbf{7 a}$ or $\mathbf{7 g}$ under the HDDA cyclization conditions. Other than $\mathbf{9}$, no product arising from an initial HDDA cyclization event was ever observed for any of the examples.

10. Woods BP, Baire B, Hoye TR. Org. Lett. 2014; 16:4578-4581. [PubMed: 25153729]

11. Hansch C, Leo A, Taft RW. Chem. Rev. 1991; 91:165-195.

12. Onishchenko AS. Diene Synthesis (Israel Program for Scientific Translations. 1964 Diels-Alder reactions with ethylenic and acetylenic dienophiles: Holmes HL. Org. React. 1948; 4:60.

13. a Pasto DJ, Krasnansky R, Zercher C. J. Org. Chem. 1987; 52:3062-3072.b Henry DJ, Parkinson CJ, Mayer PM, Radom L. J. Phys. Chem. A. 2001; 105:6750-6756.c Zipse H. Top. Curr. Chem. 2006; 263:163-189.

14. a Sauer J, Wiest H, Mielert A. Chem. Ber. 1964; 97:3183-3207.b Konovalov AI, Kamasheva GI, Loskutov MP. J. Org. Chem. USSR. 1973; 9:2064-2071. 
a HDDA Cascade
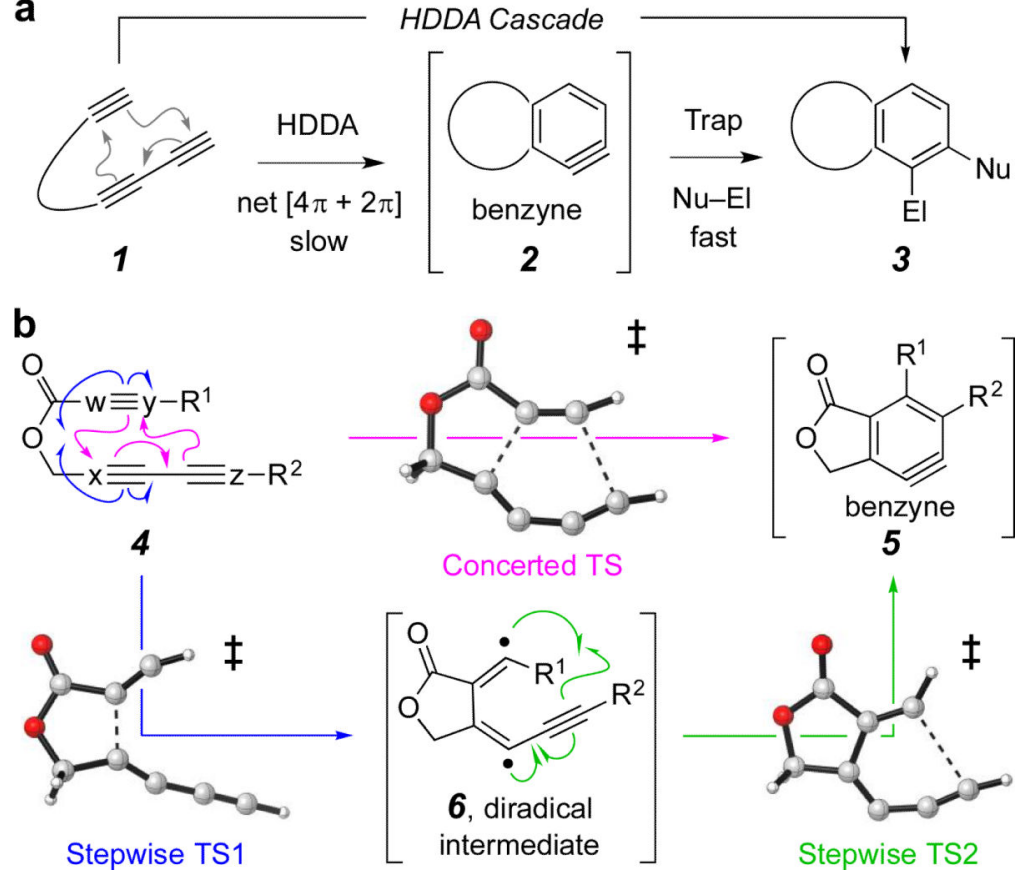

Figure 1.

a, The HDDA cascade: hexadehydro-Diels-Alder (HDDA) cyclization of triyne $\mathbf{1}$ to give benzyne intermediate $\mathbf{2}$, followed by rapid (intra- or intermolecular) trapping yielding $\mathbf{3}$. b, Concerted vs. stepwise cycloisomerization pathways. 
a

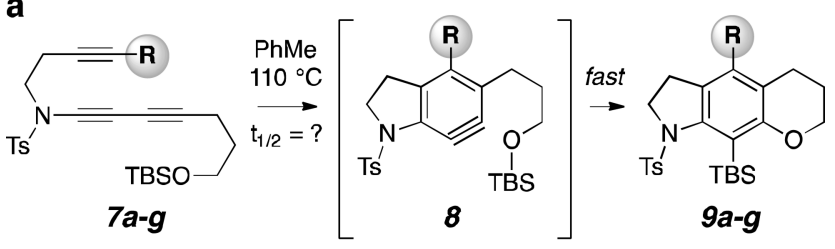

b
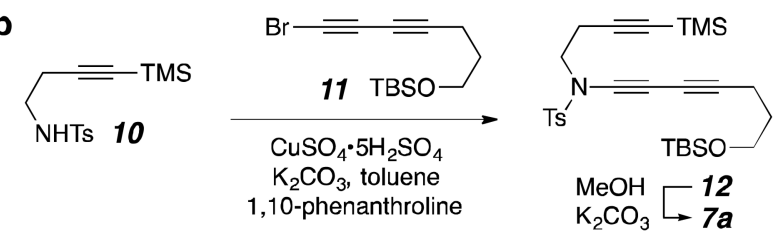

\begin{tabular}{|c|c|c|}
\hline triyne & R & conditions (from 7a) \\
\hline $7 a$ & $\mathrm{H}$ & - \\
\hline $7 b$ & $\mathrm{CONEt}_{2}$ & $\begin{array}{l}\text { 1) } n \text {-BuLi, THF, } \mathrm{CO}_{2} \\
\text { 2) } \mathrm{EDCl}, \mathrm{Et}_{2} \mathrm{NH}, \mathrm{DMAP}, \mathrm{DMF}\end{array}$ \\
\hline $7 c$ & $\mathrm{CO}_{2} \mathrm{Me}$ & n-BuLi, THF, $\mathrm{ClCO}_{2} \mathrm{Me}$ \\
\hline $7 d$ & COMe & $n$-BuLi, THF, $\mathrm{Ac}_{2} \mathrm{O}$ \\
\hline $7 e$ & $\mathrm{CHO}$ & $\begin{array}{l}\text { 1) } n \text {-BuLi, THF, }\left(\mathrm{CH}_{2} \mathrm{O}\right)_{n} \\
\text { 2) DMP, } \mathrm{NaHCO}_{3}, \mathrm{CH}_{2} \mathrm{Cl}_{2}\end{array}$ \\
\hline $7 f$ & $\mathrm{C} \equiv \mathrm{C}-\mathrm{Me}$ & $\begin{array}{l}\text { 1-bromoprop-1-yne, CuCl, } \\
\mathrm{NH}_{2} \mathrm{OH} \cdot \mathrm{HCl}, n-\mathrm{BuNH}_{2}, \mathrm{CH}_{2} \mathrm{Cl}_{2}\end{array}$ \\
\hline $7 g$ & $\mathrm{CF}_{3}$ & $\mathrm{TMSCF}_{3}, \mathrm{Cul}, \mathrm{K}_{2} \mathrm{CO}_{3}, \mathrm{TMEDA}$, DMF, air \\
\hline
\end{tabular}

Figure 2.

a, HDDA cycloisomerization of triynes $\mathbf{7 a - g}$ to form indoline derivatives $\mathbf{9 a - g}$ via benzynes 8. $\mathbf{b}$, Synthesis of $\mathbf{7 a}$ and conditions for its conversion to $\mathbf{7 b - g}$. 

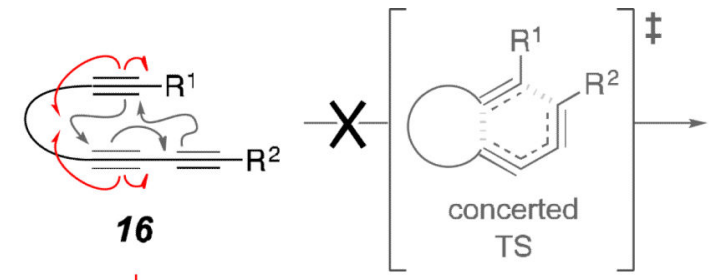<smiles>[R]c1ccc2c(c1[R])CCCCC2</smiles>

$\downarrow$ r.d.s.

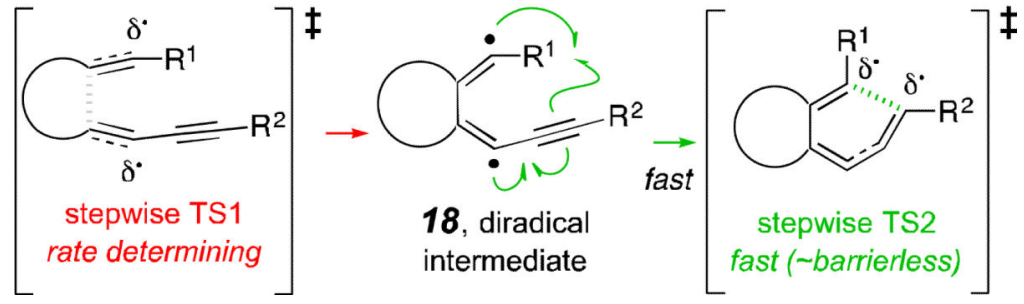

Figure 3.

The HDDA cycloisomerization (i.e., 16 to 17) proceeds via diradical 18 rather than through a "concerted TS" geometry; the relative rate data indicate that the "stepwise TS1" defines the rate of reaction. 


\section{Table 1}

Relative HDDA reaction rates of triynes 7a-g and their comparisons with $\sigma_{\mathrm{p}}$ (Hammett constant) and radical stabilizing energies (RSEs)

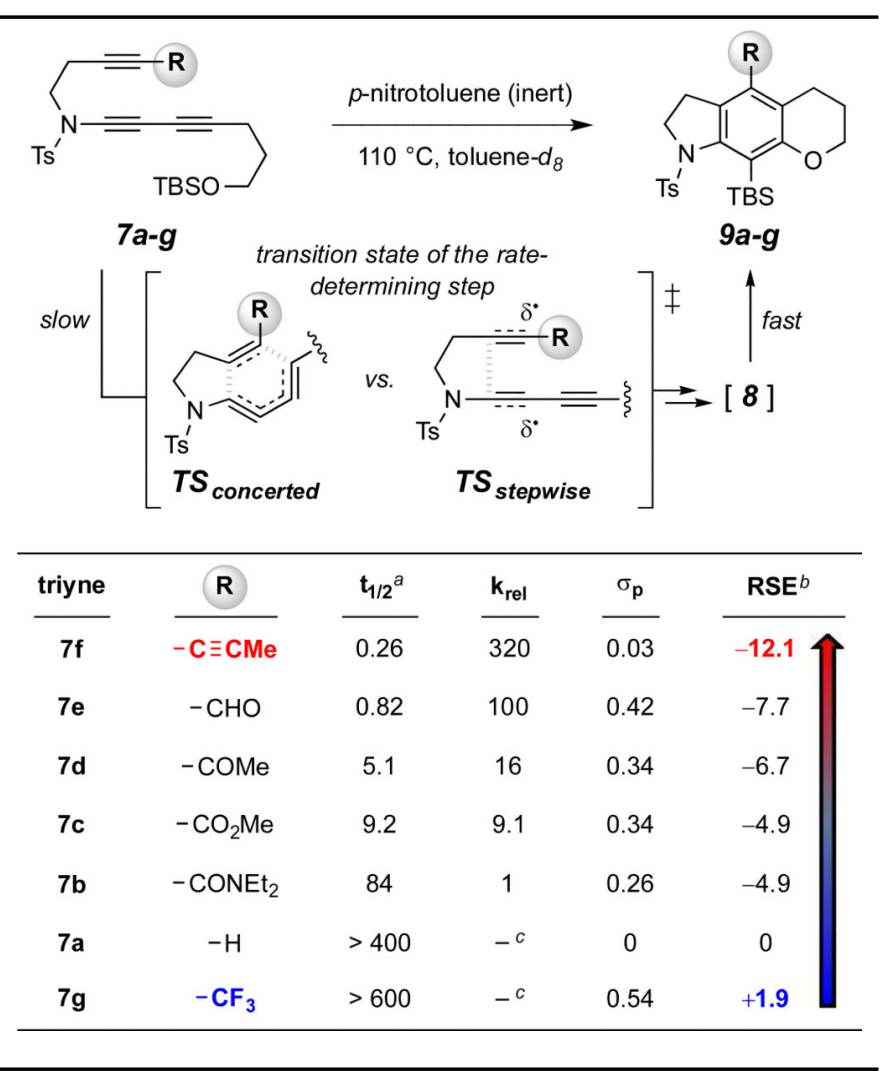

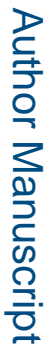

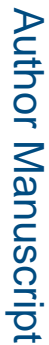




\section{Table 2}

Relative rates of Diels-Alder cycloadditions of alkynes 13a-g with cyclopentadiene (14)

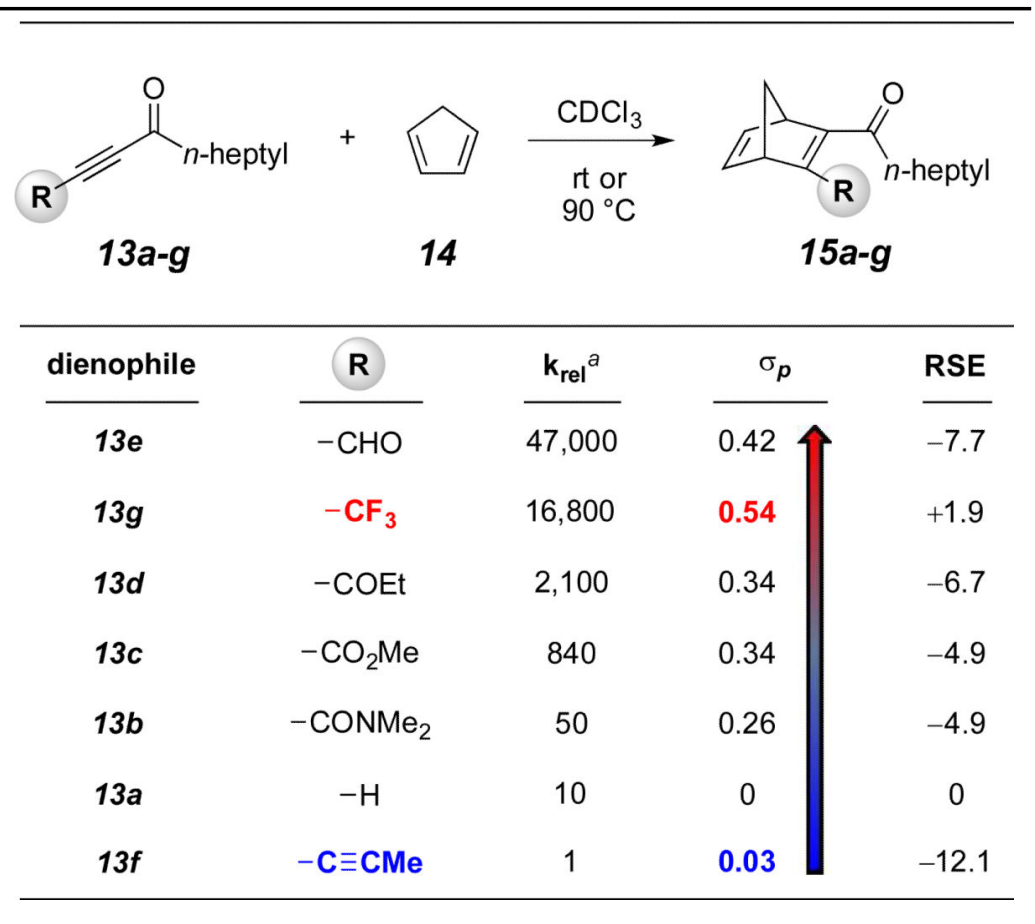

